\title{
1 Suppression of Global Protein Translation in SARS-CoV-2 Infection
}

2 Haripriya Parthasarathy*,1, Divya Gupta*, ${ }^{\star}$ Abhirami P Suresh ${ }^{\S, 1}$, Dixit Tandel ${ }^{\S, 1,2}$, Vishal

$3 \operatorname{Sah}^{1,2}$, and Krishnan Harinivas Harshan ${ }^{£, 1}$

$4 \quad$ *These authors contributed equally

5 §These authors contributed equally

$6 \quad{ }^{1}$ CSIR-Centre for Cellular and Molecular Biology, Hyderabad, India 500007

$7 \quad{ }^{2}$ Academy for Scientific and Innovative Research (AcSIR), Ghaziabad-201002, India

8

$9 \quad{ }^{€}$ Correspondence: hkrishnan@ccmb.res.in

11 Keywords

12 SARS-CoV-2, COVID-19, Global translation, mTORC1, Polysome profiling, 5'-TOP 


\section{ABSTRACT}

The relationship of SARS-CoV-2 with the host translation remains largely unexplored. Using polysome profiling of SARS-CoV-2 infected Caco2 cells, we here demonstrate that the virus

21 induces a strong suppression of global translation by 48 hours of infection. Heavy polysome

22 fractions displayed substantial depletion in the infected cells, indicating the loss of major translational activities in them. Further assessment of the major pathways regulating translation in multiple permissive cell lines revealed strong elF4E dephosphorylation accompanied by Mnk1 depletion and ERK1/2 dephosphorylations. p38MAPK showed consistent activation and its inhibition lowered viral titers, indicating its importance in viral survival. mTORC1 pathway showed the most profound inhibition, indicating its potential contribution to the suppression of global translation associated with the infection. Pharmacological activation of mTORC1 caused a drop in viral titers while inhibition resulted in higher viral RNA levels, confirming a critical role of $\mathrm{mTORC} 1$ in regulating viral replication. Surprisingly, the infection did not cause a general suppression of 5'-TOP translation, as evident from the continued expression of ribosomal proteins. Our results collectively indicate that the differential suppression of mTORC1 might allow SARS-CoV-2 to hijack translational machinery in its favor and specifically target a set of host mRNAs.

\section{INTRODUCTION}

Severe acute respiratory syndrome- coronavirus 2 (SARS-CoV-2) is responsible for the current pandemic COVID-19 that has been wreaking havoc across the world, infecting millions and causing the death of over 3.22 million people over the past year (1). The newest member of the family Coronaviridae is a $\beta$-coronavirus with an approximately 30 kb long RNA genome with positive polarity. The enveloped viral particles are 
42 characteristic of coronaviruses, binds to angiotensin converting enzyme 2 (ACE2) found

43 on the surfaces of several cells acting as the entry receptor for the virus (2). The virus enters through endocytosis and its genetic material is released into the cytosol after the endosome-lysosome fusion results in the unpacking of the virion.

After its release into the cytosol, SARS-CoV-2 RNA undergoes translation as in other

47 positive stranded RNA viruses $(3,4)$. The preliminary rounds of translation synthesize long polypeptides pp1a and pp1ab from ORFs 1a and 1ab respectively. These polypeptides are later cleaved by proteases to generate about sixteen functional polypeptides which together form the replicase complex (5). In addition to these ORFs, with common 3'-UTRs. Translation of these mRNAs is believed to be temporally regulated (6), possibly indicating its significance in the viral life-cycle.

Viruses establish a unique relationship with the host protein translation machinery. The general understanding is that viruses are total parasites on the host translation and hijack this machinery for translating their own protein. This often provides the virus an unhindered access to the machinery to keep synthesizing its proteins. However, various viruses have distinct requirements based on their nature of relationship with the hosts. Viruses such as poliovirus completely shut down host translation and use the machinery

60 for its own translation using a cap-independent mechanism (7). Several other viruses

61 inhibit host translation to varying degrees while allowing a set of mRNAs to translate (4,

62 8). Yet, some other viruses such as hepatitis $\mathrm{C}$ virus (HCV) do not cause an apparent suppression of host translation, but still use a cap-independent mechanism for their

64 translation. Members of Flaviviridae have a 5' capped genome but seem to be resistant 
to the translational arrest imposed by them even though it affects host mRNAs (9).

Coronaviruses are known to inhibit host protein translation $(6,10-13)$. Nsp1 is reported

to interfere with host translation through its interaction with $40 \mathrm{~S}$ ribosomes $(6,14-17)$.

Reports also indicate that translation efficiency of viral mRNAs are not higher than the host mRNAs, but SARS-CoV-2 mediated preferential destruction of host mRNAs lead to their reduced translation events $(6,18)$. However, the molecular mechanisms remain much elusive.

Global translation activities in higher eukaryotes are regulated by three major pathways. mTORC1 pathway is the most studied of these and is known to regulate translation of a sub-set of mRNAs with a $5^{\prime}$ terminal oligo pyrimidine (TOP) stretch (19-21). mTORC1 is active in metabolically active cells and promotes translation by facilitating the free availability of the cap-binding protein elF4E (22). One of the substrates of mTORC1, elF4E binding protein (4EBP), inhibits translation activities by sequestering elF4E (23). mTORC1 mediated phosphorylation of 4EBP lowers its affinity towards elF4E thereby making it available for cap-binding. mTORC1 also facilitates translation by phosphorylating ribosomal protein rpS6 (24), elF4B and helicase elF4A through p70S6K (25). Several viruses are reported to target mTORC1 in order to suppress host translation activities (13). Inhibition of mTORC1 is known to cause a major drop in active polysomes and translation activities $(20,21)$. MAPKs p38 and ERK1/2 are known to regulate the phosphorylation of elF4E through 85 their substrate Mnk1/2 $(26,27)$. Even though Mnk mediated phosphorylation of elF4E does not alter its affinity for the 5' cap of the mRNAs, phosphorylated elF4E is

87 commonly detected in several cancers leading several researchers to hypothesize that 
88 this phosphorylation results in preferential translation of a set of mRNAs $(28,29)$. A third

89 mechanism of regulation of global translation is the phosphorylation of elF2a at S52, a key event leading to reduced recycling rate of elF2 ternary complexes that is critical for new events of translation initiations (30). Four kinases known as integrated stress response kinases coordinate this phosphorylation relaying various upstream signals.

93 Protein kinase $\mathrm{R}(\mathrm{PKR})$, a dsRNA binding protein is one of these kinases that

94 phosphorylates elF2 $\alpha$ after the detection of dsRNA replication intermediates in the cytosol. This results in severe translational suppression in the virus infected cells as demonstrated in several cases $(31,32)$. Coronavirus genome is 5' capped and polyadenylated indicating that they use the capdependent translation machinery. However, other coronaviruses were reported to inhibit host translation by various means (11). In this study, we investigated the relationship of SARS-CoV-2 with host translation machinery and regulatory networks. We demonstrate this translational decline. p38MAPK was phosphorylated throughout the course of the infection and its inhibition also resulted in lower viral titer. SARS-CoV-2 targeted Mnk1 levels thereby limiting elF4E phosphorylation. The strongest inhibition was visible in the mTORC1 pathway where its substrates 4EBP1 and ULK1 showed loss in levels and phosphorylation. Our studies demonstrate that SARS-CoV-2 infection causes severe arrest of host translation machinery most likely through strong mTORC1 inhibition without impacting its own protein synthesis and suggests that the viral mRNAs employ 110 unique means to continue their translation under these conditions. 


\section{RESULTS}

112

113

114

115

116

117

118

119

120

121

122

123

124

125

126

127

128

129

130

131

132

\section{Polysome profiles of SARS-CoV-2 infected cells demonstrate severe collapse of}

\section{polysomes}

We performed polysome profiling of Caco2 cells infected with SARS-CoV-2 (hCoV19/India/TG-CCMB-O2-P1/2020) at multiple time intervals to map any changes in the global translation activity. The virus established infection by 24 hours post infection (hpi)

as evident from the high levels of expression of the viral nucleocapsid $(\mathrm{N})$ that continued until 96 hpi (Figure 1A). The expression of spike (S) peaked at 72 hpi and dropped thenceforth. Viral RNA replication increased until 72 hpi (Figure 1B). Interestingly, no major impact on polysome profiles was seen at 24 hpi while 48 hpi marked a remarkable collapse of polysomes with a modest swelling of the 805 peaks from 48 hpi (Figure $1 \mathrm{C}-\mathrm{F}$ ). The heavy polysomes were particularly affected and this trend remained true until 96 hpi (Figure $1 \mathrm{C}-\mathrm{F}$ ). Polysome profiling of cells infected with another strain of SARS-CoV-2 (hCoV-19/India/TG-CCMB-L1021/2020) induced an earlier collapse of the polysomes but confirmed the impact on the polysomes (Figure S1 A-D). Even though the polysomes underwent substantial dissociation, only a moderate swelling of the 805 was visible. This could be possibly due to the reported loss of host mRNAs by a selective degradation method initiated by Nsp1 of SARS-CoV-2 (16). At the same time, the translation of viral proteins continued unaffected (Figure 1A), confirming that the polysome dissociation is specifically targeting host mRNAs.

\section{SARS-CoV-2 infection does not cause elF2 $\alpha$ phosphorylation during the}

\section{suppression of translation activities}


133 elF2a phosphorylation mediated inhibition of translation initiation is frequently observed

134 in several viral infections including SARS-CoV. In addition to the activation of PKR by dsRNA, interferon has also been demonstrated to cause elF2a phosphorylation

136 mediated translational arrest (33). We analyzed this modification in SARS-CoV-2

137 infected Caco2 cells. A modest increase in elF2a phosphorylation observed at 24 and

$13848 \mathrm{hpi}$ in the infected cells disappeared soon while a prominent collapse of polysome

139

140

141

142

143

144

145

146

147

148

149

150

151

152

153

154

was apparent (Figure 2). A similar observation was made in the infected Calu-3 cells as well (Figure S2A) despite a robust viral replication (Figure S2B) validating that SARS CoV-2 mediated translational arrest is not mediated through elF2a phosphorylation. On the other hand, the infected Huh7 cells (Figure S2C) exhibited a curious increase in elF2a phosphorylation throughout the course of infection, indicating a possible cell-type specific effect on the ISR pathway (Figure S2D). Since no elF2a phosphorylation was evident concurrent with the collapse of polysomes in Caco2, this molecule is unlikely to have contributed to the translational suppression.

\section{ERK1/2-Mnk1/2-elF4E is inhibited during SARS-CoV-2 infection}

elF4E phosphorylation is often targeted under several physiological conditions and in certain viral infections $(4,8)$. We tested if SARS-CoV-2 targets this molecule in order to suppress host translation in Caco2 cells. Viral infection impacted the levels of several of the key molecules in this pathway beyond 48 hours of infection and hence we normalized the phosphorylation of these molecules and their abundance separately with the loading control. A moderate dephosphorylation of elF4E at S209 residue was visible from 24 hours of infection (Figure 3). 
Mnk1, the kinase that phosphorylates elF4E, is regulated by two MAPKs, p38 and

$$
\text { ERK1/2. Either of them has been demonstrated to activate Mnk1 through its }
$$
phosphorylation. Mnk1 associated with elF4G, the scaffold initiation factor of elF4F complex, is activated upon phosphorylation and subsequently phosphorylates elF4E. In agreement with the elF4E dephosphorylation, Mnk1 also underwent dephosphorylation in SARS-CoV-2 infected cells (Figure 3), suggesting that the upstream MAPKs could be targeted by the viral infection. We subsequently analyzed the activation of the two MAPKs during SARS-CoV-2 infection in Caco2 cells. Consistent with the elF4E and Mnk1 dephosphorylations, ERK1/2 dephosphorylation was evident in the infected cells from 24 hpi onwards, indicating that the upstream signals to ERK1/2 have been targeted during the infection (Figure 3). Major dephosphorylation of ERK1/2 and elF4E was evident from 48 hpi in Huh7 cells as well (Figure S3). These results demonstrate that ERK1/2-Mnk-elF4E pathway is targeted by SARS-CoV-2 infection at the abundance levels of the component molecules and additionally at their phosphorylation levels.

\section{p38MAPK phosphorylated during SARS-CoV-2 infection is beneficial to the viral} replication

\section{Unlike ERK1/2, p38MAPK was phosphorylated in SARS-CoV-2 infected cells}

throughout the duration. The phosphorylation increased with time, with the most intense phosphorylation detected at $96 \mathrm{hpi}$, suggesting that this MAPK might be very important for the viral activities (Figure 4A). We tested this hypothesis by inhibiting SARS-CoV-2 infected Caco2 cells for 24 hours. The effect of inhibition of elF4E phosphorylation was less remarkable in the infected cells as compared with the mock cultures similarly 
178 inhibited, indicating the pressure from the viral replication. As we expected, inhibition of p38MAPK, confirmed by the dephosphorylation of elF4E (Figure 4B), resulted in significantly lower intracellular viral RNA (Figure 4C) and infectious viral titer in the supernatant (Figure 4D) as compared against the untreated control culture. These results indicated that p38MAPK is activated in SARS-CoV-2 infected cells through specific upstream signals and this molecule plays important roles in SARS-CoV-2 biology.

\section{SARS-CoV-2 inhibits mTORC1 and depletes its key substrates}

4EBP1 is a key substrate of $\mathrm{mTORC} 1$ through which the complex regulates translation initiation. Active mTORC1 phosphorylates T37/46 in 4EBP1, causing a reduction in its affinity for elF4E. This phosphorylation triggers phosphorylations at additional sites and the hyperphosphorylated 4EBP1 migrates slowly as compared with the hypo- and partly phosphorylated molecules. We analyzed the kinetics of phosphorylation of 4EBP1 during SARS-CoV-2 infection in Caco2 cells. As demonstrated in Figure 5A, 4EBP1 phosphorylation was significantly reduced in SARS-CoV-2 infected cells from 48 hpi onwards. As in the case of ERK1/2-elF4E pathway, 4EBP1 was also depleted in the infected cultures. Despite this depletion, the dephosphorylation was more intense,

195 indicating that mTORC1 activity was inihibited. p70S6K1 and ULK1, two other major substrates of mTORC1 were also dephosphorylated in these samples, further confirming the loss of activity of the kinase complex. Interestingly, dephosphorylation was accompanied by a significant loss in the levels of all these proteins as well, 
201 mechanism across cell types (Figure S4A). Recent reports have demonstrated a global

202

203

204

205

206

207

208

209

210

211

212

213

214

215

216

217

218

219

220 221 set of mRNAs.

222

decay of host mRNA possibly driven by Nsp1 during SARS-CoV-2 infection $(6,18)$. We

investigated the association of the loss of 4EBP1 and ULK1 upon infection with a

potential degradation of their transcripts using quantitative RT-PCR and surprisingly

detected significantly elevated levels of their transcripts in the infected cells indicating

the involvement of post-transcriptional regulations (Figure $5 \mathrm{~B}$ and $\mathrm{C}$ ). Thus, these

transcripts are not part of the host mRNAs specifically degraded by viral proteins. These

results demonstrate that SARS-CoV-2 targets mTORC1 pathway by suppressing its

activity as well by targeting the expression of the key molecules in the pathway. Active

viral translation during severe inhibition of $\mathrm{mTORC} 1$ indicates that $\mathrm{mTORC} 1$ is

dispensable for the translation of SARS CoV-2 proteins.

Since mTORC1 regulates translation of a large number of transcripts including those

encoding ribosomal proteins through 5' TOP elements, we asked if the inhibition of

mTORC1 pathway negatively impacts ribosomal biogenesis. Analysis of ribosomal

proteins rpS3, rpL13a and rpL26 revealed that their expressions are not affected by

SARS-CoV-2 infection (Figure 5D). Thus, despite a strong polysome dissociation and

inhibition of $\mathrm{mTORC1}$, ribosomal protein synthesis goes on unabated indicating that

inhibition of mTORC1 activity is not affecting the translation of 5 ' TOP mRNAs. This part

of the data suggests that SARS-CoV-2 brings about translational suppression through a remarkable inhibition of $\mathrm{mTORC} 1$ and the suppression could be selectively targeting a

\section{mTORC1 restricts SARS CoV-2 replication}


223 Since SARS CoV-2 infection caused strong suppression of mTORC1, we investigated whether this inhibition benefits the virus. Huh7 cells infected with SARS CoV-2 for 24

225 hours were treated with $10 \mu \mathrm{M}$ MHY1485 to activate mTORC1. The drug failed to

226 induce mTORC1 activity (4EBP1 phosphorylation) in the virus infected cells while its

227 activation was detected in the mock-infected cells (Figure 6A), indicating that the virus

228 infection overrides the activation of mTORC1 by the drug. Interestingly, activation of

229 mTORC1 resulted in decreased intracellular RNA as well as infectious titer of the virus

230 (Figure $6 \mathrm{~B}$ and $\mathrm{C}$ respectively). In agreement with this observation, a moderate drop in

231 the nucleocapsid levels was also visible (Figure 6A). These observations suggest that

232 lower mTORC1 activity is beneficial for SARS-CoV-2 replication.

233 Next, we inhibited mTORC1 by Torin1 and investigated its effect on the infection. After

234 infecting the cells with SARS CoV-2 for 2 hours, they were treated with 750 nM Torin1

235 until 24 hpi before analyzing the intracellular viral RNA. mTORC1 inhibition, confirmed

by the dephosphorylation of 4EBP1 (Figure 6D), caused a two-fold increase in

237 intracellular viral RNA levels (Figure 6E), strengthening the observations made in the

238 preceding experiment that mTORC1 inhibition favors the viral replication. Our results

239 indicate that $\mathrm{mTORC1}$ inhibition might facilitate SARS-CoV-2 replication.

\section{DISCUSSION}

241 Several studies have indicated that SARS-CoV-2 infection suppresses host protein

242 translation $(2-4,6,12)$. While some have speculated this observation based on the

243 reports from similar $\beta$-coronaviruses, others have implicated this based on the host

244 mRNA degradation mediated by SARS-CoV-2 Nsp1 $(6,18)$. Nsp1 was also shown to

245 associate with $40 \mathrm{~S}$ ribosomes and block the entry of mRNAs (15). Our study provides a 
246 detailed map of the impact of SARS-CoV-2 on global translation and the signal

247 pathways that regulate the process. Polysome profile kinetics provided striking evidence

248 of the suppression of host translation from around $48 \mathrm{hpi}$.

249 Even as other studies have reported global degradation of host mRNAs $(6,17)$, we

250 have not come across any evidence that testifies this observation from our studies.

251 Widespread host mRNA degradation would have resulted in the accumulation of the

252 short and free nucleotides in mRNP fractions that our studies have not observed.

253 Similar studies done in our laboratory using a flavivirus JEV show a significant swelling

254 in 80 s peaks concurrent with polysome dissociation as infection progressed, which

255 wasn't as apparent in SARS-CoV-2 infected cells (data not shown). The fact that the

25680 s peak did not undergo any shortening at the later time intervals suggested that a

257 significant fraction of mRNAs are still associated with monosomes and could be

258 translation-ready, as is evidenced by a sustained maintenance of lighter polysomes

259 throughout the course of infection. Thus, a considerable proportion of the host mRNA

260 population is likely to be intact despite being subject to specific degradation by viral

261 factors. Justifying this claim, 4EBP1 and ULK1 mRNAs were detected at significantly

262 higher levels in the infected cells. This could have been a reflection of their

263 transcriptional activation or enhanced stabilization of the transcripts, either of which

264 indicates that they are not subject to degradation. Nsp1 mediated blocking of the host

265 mRNAs from accessing 40 S ribosomes might also have resulted in significant drop in

266 the $80 \mathrm{~S}$ assembly. However, a clear enlargement of $80 \mathrm{~S}$ fraction was visible in cells

267 expressing Nsp1 (17) indicating that the regulation is more complex. Interestingly, no

268 such information is available for MERS in the literature. Further detailed studies are 

276 infected cells.

necessary to understand the larger impact of SARS-CoV-2 infection on $80 \mathrm{~S}$ and polysome assembly.

We have observed a systematic depletion of several host proteins during the course of viral infection, particularly at later stages. Majority of these included substrates of mTORC1 and members of MAPK pathway. Since 4EBP1 and ULK1 were not subject to mRNA degradation, it is very apparent that post-transcriptional and post-translational mechanisms targeting specific host proteins are quite pervasive in SARS-CoV-2

mTORC1 was strongly inhibited by SARS-CoV-2. Targeting mTORC1 seems to be more concerted and with purpose since the substrates were also depleted at protein level. Justifying this point, conditions of lower mTORC1 activities promoted viral replication and its activation lowered the titers. It appears that post-transcriptional regulations play a role in their abundance in the infected cells. The implication of lower availability of 4EBP1 on the translation of host and viral mRNAs is unclear at this stage. Lower abundance of this inhibitory molecule could be interpreted to be facilitating elF4F assembly and capped translation. However, the lower activity of mTORC1 also resulted in lower p70S6K phosphorylation indicating that the net impact of its inhibition results in reduced polysome assembly and translation activities. Interestingly, ribosomal proteins that we tested remained abundantly available in the infected cells and this might be important for the translation of viral proteins. Thus, it appears that mTORC1 inhibition does not target all 5'TOP mRNAs but must be targeting a select set of mRNAs without compromising the requirements of the virus. 
291 How mTORC1 inhibition is brought about by SARS-CoV-2 is unclear. A recent study

292 (34) reported that SARS-CoV-2 rewires metabolic pathways in the infected cells that

293 results in enhanced mTORC1 activity. However, this study was limited to 24 hpi which is

294 quite early in the context of an ongoing infection. Our study also indicated an early,

295 albeit modest, activation of mTORC1. However, the inhibition accompanied by the loss

296 of substrates at later time points was very consistent and strong in more than one cell

297 line. In the context of altering metabolic activities during infection, it appears that the

298 metabolic networks are manipulated differently during the distinct phase of infection and

299 this may have a significant bearing on the outcome of infection.

300 elF4E phosphorylation is dependent on the activities of ERK1/2 and p38MAPK. It is

301 curious to note that only ERK1/2, but not p38MAPK, was dephosphorylated by SARS-

302 CoV-2 mediated signaling activities. Unpublished results from our laboratory have

303 indicated synergistic regulation of Mnk1 by these MAPKs. Curiously, Mnk1 was also

304 targeted at the protein level by the virus and this must have significantly impacted elF4E

305 phosphorylation. Since elF4E phosphorylation is understood to affect only a select set

306 of mRNAs translationally (35), we believe that its contribution to the global suppression

307 of translation activities caused by SARS-CoV-2 infection could be limited and more

308 studies are necessary to determine its impact. The consequence of p38MAPK

309 phosphorylation and possible activation of this molecule in SARS-CoV-2 infection is

310 very evident from the inhibition studies. The drop in viral titer was modest, but

311 proportionate to the magnitude of inhibition. Whether this has any impact on the

312 translation of viral proteins is to be determined. 
313 It is intriguing why SARS-CoV-2 infection does not induce elF2a phosphorylation. elF2a

314 is phosphorylated by one of its four kinases most of which are activated upon various

315 stress exerted on the cell. RNA viruses often impart intense stress on ER that is relayed

316 to PERK $(36,37)$. PKR, one of the dsRNA sensors is often activated by RNA viral

317 infections. These observations indicate that SARS-CoV-2 depends on the canonical

318 mechanism of translation initiation that requires the availability of active ternary

319 complexes, which elF2a is a part of. Since elF2a phosphorylation results in the

320 inhibition of new initiation events that would adversely affect the translation of viral

321 transcripts as well, SARS-CoV-2 might have evolved strategies to bypass this

322 modification.

323 Materials and Methods

324 Antibodies and inhibitors

325 All primary antibodies were purchased from Cell Signaling Technologies except the anti-

326 SARS Spike antibody (Novus Biologicals; NB100-56578) and anti-SARS-CoV-2

327 Nucleocapsid (Thermo Fisher; MA5-29982). HRP-conjugated anti-rabbit and anti-mouse

328 secondary antibodies were purchased from Jackson ImmunoResearch. Torin1 and

329 MHY1485 were from Sigma, whereas the p38 VIII inhibitor was from Cayman

330 Chemicals.

331 Cell culture

332 Vero (CCL-81) African green monkey kidney epithelial cells, Huh7 human hepatoma

333 cells and Calu3 lung adenocarcinoma cells were cultured in Dulbecco's Modified 
334 Eagle's Medium (DMEM; from Gibco) with 10\% Fetal Bovine Serum (FBS; Hyclone) and

$3351 \times$ penicillin-streptomycin cocktail (Gibco) at $37^{\circ} \mathrm{C}$ and $5 \% \mathrm{CO}_{2}$. Colorectal

336 adenocarcinoma Caco2 cells, were grown in DMEM supplemented with 20\% FBS and

$3371 \times$ antibiotic. Cells were continuously passaged at $70-80 \%$ confluency and mycoplasma

338 contamination was monitored periodically.

\section{SARS-CoV-2 Infection and quantification}

340 Two Indian isolates of SARS-CoV-2 strains were used in this study (GSSAID id:

341 EPI_ISL_458075 and EPI_ISL_458046) $(38,39)$. All the viral cultures were propagated

342 in Vero (CCL-81) cells in serum and antibiotics free conditions. Caco2, Huh7 or Calu-3

343 cells were infected at $1 \mathrm{MOI}$ for 2 hours in serum-free conditions after which the media

344 was replaced with complete media and further incubated until the time of harvesting. At

345 the time of harvesting, the cells were first trypsinized and collected separately for

346 protein and RNA study. The intracellular and extracellular RNA from cells was isolated

347 using respective kits (MACHEREY-NAGEL GmbH \& Co. KG) and the SARS-CoV-2

348 RNA was quantified using a commercial kit (LabGun ${ }^{\text {TM }}$ COVID-19 RT-PCR Kit)

349 following manufacturers protocol in Roche LightCycler 480. For intracellular SARS-

350 CoV-2 RNA, the normalization was performed against GAPDH after preparing cDNA in

351 two-step reactions (Primescript, Takara Bio). The infectious viral particle numbers in the

352 supernatant were quantified using plaque-forming unit (PFU/mL) assay. Briefly, the

353 supernatant was log diluted $\left(10^{-1}-10^{-7}\right)$ in $1 \times$ serum-free DMEM and used for infecting

354 Vero monolayer grown in six- or twelve-well plates. 2 hpi, the cells briefly washed and

355 were overlaid with agarose: DMEM mix (in 1:1 ratio; 2 x DMEM with 5\% FBS and 1\%

356 penicillin-streptomycin mixed with equal volumes of $2 \%$ LMA), after which the plates 
357 were incubated undisturbed for 6 days at $37^{\circ} \mathrm{C}$. Later, the cells were fixed with $4 \%$

358 formaldehyde and stained with crystal violet. The clear zones were counted and PFU was calculated as PFU/mL.

\section{Inhibitions and infection}

361 Torin1 inhibition and MHY1485 activation were done in Huh7 cells. For the Torin1

362 inhibition experiment, $0.45 \times 10^{6}$ cells were seeded in a six-well format and 24 hours

363 later the cells were infected with SARS-CoV-2, at $1 \mathrm{MOI}$ for 2 hours in serum-free

364 media. Later, the infection media was replaced with serum sufficient media containing

$365750 \mathrm{nM}$ Torin1 or DMSO, and incubated for $22 \mathrm{hrs}$. At the end of the treatment, the cells

366 were harvested and protein and RNA were prepared. For the activation of $\mathrm{mTORC1}$,

367 cells were treated with $\mathrm{MHY} 1485$ at 24 hpi at $10 \mu \mathrm{M}$ concentration and harvested at 48

368 hpi. The p38 inhibition was carried out in Caco2 cells similar to the MHY1485

369 experiment. The intracellular and extracellular RNA were subjected to qRT-PCR, and 370 the protein lysates were subjected to western blotting for confirmation of inhibition or 371 activation.

\section{Polysome preparation}

373 Polysomes were fractionated as explained elsewhere (40). Caco2 cells were grown in

$374175 \mathrm{~cm}^{2}$ flasks till $70 \%$ confluency and subsequently infected with SARS-CoV-2 at 1

375 MOI. Media was changed after 2 hours, and cells were harvested at 24, 48 72, and 96

376 hpi, along with mock-infected cells grown alongside for each time point.

377 The cells were incubated for 5-10 minutes, harvested and washed twice with a solution

378 of ice-cold $1 \times$ PBS containing $100 \mu \mathrm{g} / \mathrm{mL}$ cycloheximide, to freeze the polysomes on the 
379 mRNAs. They were subsequently lysed in polysome lysis buffer containing 20 mM TrisCl pH 8.0, 140 mM KCl, 1.5 mM MgCl2, 0.5 mM DTT, 1\% Triton X-100, 1× protease was quantified using a spectrophotometer, and $90 \mu \mathrm{g}$ was layered onto $11 \mathrm{~mL}$ of 10 $50 \%$ linear sucrose gradient (20 mM Tris-Cl pH 8.0, $140 \mathrm{mM} \mathrm{KCl,} 1.5 \mathrm{mM} \mathrm{MgCl}$, 0.5 mM DTT, $100 \mu \mathrm{g} / \mathrm{mL}$ cycloheximide, $1 \mathrm{mM}$ PMSF, 10-50\% sucrose). The resulting gradients were centrifuged in an SW41 Ti rotor (Beckman Coulter) at 35,000 r.p.m. at $4^{\circ} \mathrm{C}$ for 3.5 hours. The polysome samples were fractionated using Teledyne ISCO fraction collector system and absorbance measured and graphically noted at $254 \mathrm{nM}$. Polysome profiles of mock and infected cells for each time point were digitized and overlaid on Inkscape.

\section{Immunoblotting}

Protein pellets were lysed in $1 \times$ Nonidet P-40 lysis buffer (1\% Nonidet P-40, 50 mM Tris $\mathrm{HCl}, 150 \mathrm{mM} \mathrm{NaCl}(\mathrm{pH} 7.5)$, EGTA, 1 mM sodium orthovanadate, 10 mM sodium pyrophosphate, $100 \mathrm{mM} \mathrm{NaF}$, and $1 \mathrm{mM}$ PMSF) incubated on ice for 20

394 minutes with intermittent vortexing and centrifuged at $13000 \mathrm{rpm}$ for 15 minutes at $4^{\circ} \mathrm{C}$.

395 The supernatants containing the proteins were collected and quantified using BCA

396 reagents (G Biosciences). Lysates were mixed with $6 \times$ denaturing dye and the proteins were resolved using SDS-PAGE and transferred to PVDF membranes. The membranes were blocked in 5\% BSA dissolved in 1× TBST before the addition of primary

399 antibodies. Primary antibodies against the proteins of interest were diluted in the 
402 added and the blots were developed on a Bio-Rad Chemidoc MP system using

403 SuperSignal West Pico PLUS (Thermo Fisher) and SuperSignal West Femto Maximum

404 Sensitivity (Thermo Fisher) chemiluminescent substrate kits.

405 Statistical analysis

406 For each experiment, at least three independent replicates were used to calculate mean

$407 \pm$ SEM, and plotted graphically wherever indicated. Statistical significance was

408 measured using two-tailed, unpaired Student $t$-test and the resultant $p$ values were

409 represented as $*,{ }^{* *},{ }^{* *}$ indicating $p$ values $\leq 0.05,0.005$, and 0.0005 , respectively.

410 Institutional biosafety

411 Institutional biosafety clearance was obtained by K.H.H., for the experiments pertaining to

412 SARS-CoV-2.

\section{Acknowledgements}

414 We thank Mohan Singh Moodu and Amit Kumar for assisting with logistics and Karthika

415 S Nair for her assistance with some experiments

418 Funding

419 This study was supported by internal funding from Council of Scientific and Industrial

420 Research (CSIR), Govt. of India. D.G., and D.K received research fellowship from 
CSIR. V.S received research fellowship from the Department of Biotechnology (DBT),

422 Govt. of India.

\section{Contributions}

424 The experiments were conceived by H.P., D.G., and K.H.H. H.P., and D.G., performed

polysome profiling. D.G., D.K., and V.S prepared SARS-CoV-2, performed infections,

quantified them and analyzed data. H.P., A.P.S., and D.K performed immunobloting.

H.P., and D.G., assisted K.H.H in writing the manuscript.

\section{References}

1. Zhou P, Yang XL, Wang XG, Hu B, Zhang L, Zhang W, Si HR, Zhu Y, Li B, Huang CL, Chen HD, Chen J, Luo Y, Guo H, Jiang RD, Liu MQ, Chen Y, Shen XR, Wang X, Zheng XS, Zhao K, Chen QJ, Deng F, Liu LL, Yan B, Zhan FX, Wang YY, Xiao GF, Shi ZL. 2020. A pneumonia outbreak associated with a new coronavirus of probable bat origin. Nature 579:270-273.

2. Shang J, Wan Y, Luo C, Ye G, Geng Q, Auerbach A, Li F. 2020. Cell entry mechanisms of SARSCoV-2. Proceedings of the National Academy of Sciences 117:11727-11734.

3. V'kovski P, Kratzel A, Steiner S, Stalder H, Thiel V. 2021. Coronavirus biology and replication: implications for SARS-CoV-2. Nature Reviews Microbiology 19:155-170.

4. Walsh D, Mohr I. 2011. Viral subversion of the host protein synthesis machinery. Nature Reviews Microbiology 9:860-875.

5. Finkel Y, Mizrahi O, Nachshon A, Weingarten-Gabbay S, Morgenstern D, Yahalom-Ronen Y, Tamir H, Achdout H, Stein D, Israeli O, Beth-Din A, Melamed S, Weiss S, Israely T, Paran N, Schwartz M, Stern-Ginossar N. 2021. The coding capacity of SARS-CoV-2. Nature 589:125-130.

6. Finkel Y, Gluck A, Winkler R, Nachshon A, Mizrahi O, Lubelsky Y, Zuckerman B, Slobodin B, Yahalom-Ronen Y, Tamir H, Ulitsky I, Israely T, Paran N, Schwartz M, Stern-Ginossar N. 2020. SARS-CoV-2 utilizes a multipronged strategy to suppress host protein synthesis doi:10.1101/2020.11.25.398578. bioRxiv.

7. Etchison D, Milburn SC, Edery I, Sonenberg N, Hershey JW. 1982. Inhibition of HeLa cell protein synthesis following poliovirus infection correlates with the proteolysis of a 220,000 -dalton polypeptide associated with eucaryotic initiation factor 3 and a cap binding protein complex. J Biol Chem 257:14806-10.

8. Jan E, Mohr I, Walsh D. 2016. A Cap-to-Tail Guide to mRNA Translation Strategies in VirusInfected Cells. Annu Rev Virol 3:283-307.

9. Edgil D, Polacek C, Harris E. 2006. Dengue Virus Utilizes a Novel Strategy for Translation Initiation When Cap-Dependent Translation Is Inhibited. Journal of Virology 80:2976-2986.

10. Kamitani W, Huang C, Narayanan K, Lokugamage KG, Makino S. 2009. A two-pronged strategy to suppress host protein synthesis by SARS coronavirus Nsp1 protein. Nature Structural \& Molecular Biology 16:1134-1140. 
11. Nakagawa K, Lokugamage KG, Makino S. 2016. Viral and Cellular mRNA Translation in Coronavirus-Infected Cells. Adv Virus Res 96:165-192.

12. Banerjee AK, Blanco MR, Bruce EA, Honson DD, Chen LM, Chow A, Bhat $P$, Ollikainen N, Quinodoz SA, Loney C, Thai J, Miller ZD, Lin AE, Schmidt MM, Stewart DG, Goldfarb D, De Lorenzo G, Rihn SJ, Voorhees RM, Botten JW, Majumdar D, Guttman M. 2020. SARS-CoV-2 Disrupts Splicing, Translation, and Protein Trafficking to Suppress Host Defenses. Cell 183:13251339.e21.

13. Stern-Ginossar N, Thompson SR, Mathews MB, Mohr I. 2019. Translational Control in VirusInfected Cells. Cold Spring Harb Perspect Biol 11.

14. Lapointe CP, Grosely R, Johnson AG, Wang J, Fernández IS, Puglisi JD. 2021. Dynamic competition between SARS-CoV-2 NSP1 and mRNA on the human ribosome inhibits translation initiation. Proc Natl Acad Sci U S A 118.

15. Schubert K, Karousis ED, Jomaa A, Scaiola A, Echeverria B, Gurzeler LA, Leibundgut M, Thiel V, Mühlemann O, Ban N. 2020. SARS-CoV-2 Nsp1 binds the ribosomal mRNA channel to inhibit translation. Nat Struct Mol Biol 27:959-966.

16. Shi M, Wang L, Fontana P, Vora S, Zhang Y, Fu TM, Lieberman J, Wu H. 2020. SARS-CoV-2 Nsp1 suppresses host but not viral translation through a bipartite mechanism. bioRxiv doi:10.1101/2020.09.18.302901.

17. Thoms M, Buschauer R, Ameismeier M, Koepke L, Denk T, Hirschenberger M, Kratzat H, Hayn M, Mackens-Kiani T, Cheng J, Straub JH, Stürzel CM, Fröhlich T, Berninghausen O, Becker T, Kirchhoff F, Sparrer KMJ, Beckmann R. 2020. Structural basis for translational shutdown and immune evasion by the Nsp1 protein of SARS-CoV-2. Science 369:1249-1255.

18. Puray-Chavez M, Tenneti K, Vuong HR, Lee N, Liu Y, Horani A, Huang T, Case JB, Yang W, Diamond MS, Brody SL, Dougherty J, Kutluay SB. 2020. The translational landscape of SARS-CoV2 and infected cells. bioRxiv doi:10.1101/2020.11.03.367516.

19. Jefferies HB, Reinhard C, Kozma SC, Thomas G. 1994. Rapamycin selectively represses translation of the "polypyrimidine tract" mRNA family. Proc Natl Acad Sci U S A 91:4441-5.

20. Thoreen CC, Chantranupong L, Keys HR, Wang T, Gray NS, Sabatini DM. 2012. A unifying model for mTORC1-mediated regulation of mRNA translation. Nature 485:109-113.

21. Hsieh AC, Liu Y, Edlind MP, Ingolia NT, Janes MR, Sher A, Shi EY, Stumpf CR, Christensen C, Bonham MJ, Wang S, Ren P, Martin M, Jessen K, Feldman ME, Weissman JS, Shokat KM, Rommel C, Ruggero D. 2012. The translational landscape of mTOR signalling steers cancer initiation and metastasis. Nature 485:55-61.

22. Hay N, Sonenberg N. 2004. Upstream and downstream of mTOR. Genes Dev 18:1926-45.

23. Ma XM, Blenis J. 2009. Molecular mechanisms of mTOR-mediated translational control. Nature Reviews Molecular Cell Biology 10:307-318.

24. Hara K, Yonezawa K, Weng Q-P, Kozlowski MT, Belham C, Avruch J. 1998. Amino Acid Sufficiency and mTOR Regulate p70 S6 Kinase and elF-4E BP1 through a Common Effector Mechanism*. Journal of Biological Chemistry 273:14484-14494.

25. Zoncu R, Efeyan A, Sabatini DM. 2011. mTOR: from growth signal integration to cancer, diabetes and ageing. Nature Reviews Molecular Cell Biology 12:21-35.

26. Pyronnet S, Imataka H, Gingras AC, Fukunaga R, Hunter T, Sonenberg N. 1999. Human eukaryotic translation initiation factor $4 \mathrm{G}$ (elF4G) recruits mnk1 to phosphorylate elF4E. Embo j 18:270-9.

27. Joshi B, Cai AL, Keiper BD, Minich WB, Mendez R, Beach CM, Stepinski J, Stolarski R, Darzynkiewicz E, Rhoads RE. 1995. Phosphorylation of eukaryotic protein synthesis initiation factor 4E at Ser-209. J Biol Chem 270:14597-603.

28. Scheper GC, Proud CG. 2002. Does phosphorylation of the cap-binding protein elF4E play a role in translation initiation? Eur J Biochem 269:5350-9. 
29. Lazaris-Karatzas A, Montine KS, Sonenberg N. 1990. Malignant transformation by a eukaryotic initiation factor subunit that binds to mRNA 5 ' cap. Nature 345:544-7.

30. Krishnamoorthy T, Pavitt GD, Zhang F, Dever TE, Hinnebusch AG. 2001. Tight binding of the phosphorylated alpha subunit of initiation factor 2 (elF2alpha) to the regulatory subunits of guanine nucleotide exchange factor elF2B is required for inhibition of translation initiation. Mol Cell Biol 21:5018-30.

31. Rojas M, Arias CF, López S. 2010. Protein kinase R is responsible for the phosphorylation of elF2alpha in rotavirus infection. J Virol 84:10457-66.

32. Bechill J, Chen Z, Brewer JW, Baker SC. 2008. Coronavirus infection modulates the unfolded protein response and mediates sustained translational repression. J Virol 82:4492-501.

33. Pham AM, Santa Maria FG, Lahiri T, Friedman E, Marie IJ, Levy DE. 2016. PKR Transduces MDA5Dependent Signals for Type I IFN Induction. PLoS Pathog 12:e1005489.

34. Mullen PJ, Garcia G, Purkayastha A, Matulionis N, Schmid EW, Momcilovic M, Sen C, Langerman J, Ramaiah A, Shackelford DB, Damoiseaux R, French SW, Plath K, Gomperts BN, Arumugaswami V, Christofk HR. 2021. SARS-CoV-2 infection rewires host cell metabolism and is potentially susceptible to mTORC1 inhibition. Nature Communications 12:1876.

35. Furic L, Rong L, Larsson O, Koumakpayi IH, Yoshida K, Brueschke A, Petroulakis E, Robichaud N, Pollak M, Gaboury LA, Pandolfi PP, Saad F, Sonenberg N. 2010. elF4E phosphorylation promotes tumorigenesis and is associated with prostate cancer progression. Proceedings of the National Academy of Sciences 107:14134-14139.

36. Pavio N, Romano PR, Graczyk TM, Feinstone SM, Taylor DR. 2003. Protein synthesis and endoplasmic reticulum stress can be modulated by the hepatitis $C$ virus envelope protein $E 2$ through the eukaryotic initiation factor 2alpha kinase PERK. J Virol 77:3578-85.

37. Su HL, Liao CL, Lin YL. 2002. Japanese encephalitis virus infection initiates endoplasmic reticulum stress and an unfolded protein response. J Virol 76:4162-71.

38. Gupta D, Parthasarathy H, Sah V, Tandel D, Vedagiri D, Reddy S, Harshan KH. 2021. Inactivation of SARS-CoV-2 by $\beta$-propiolactone Causes Aggregation of Viral Particles and Loss of Antigenic Potential. bioRxiv doi:10.1101/2021.04.22.441045:2021.04.22.441045.

39. Gupta D, Ahmed F, Tandel D, Parthasarathy H, Vedagiri D, Sah V, Krishna Mohan B, Daga S, Khan RA, Kondiparthi C, Savari P, Jain S, Daga J, Reddy S, Khan N, Harshan KH. 2021. Development of Equine Immunoglobulin Fragment $\mathrm{F}\left(\mathrm{ab}^{\prime}\right)_{2}$ with High Neutralizing Capability against SARS-CoV-2. bioRxiv doi:10.1101/2021.03.09.434030:2021.03.09.434030.

40. George A, Panda S, Kudmulwar D, Chhatbar SP, Nayak SC, Krishnan HH. 2012. Hepatitis C virus NS5A binds to the mRNA cap-binding eukaryotic translation initiation 4F (elF4F) complex and upregulates host translation initiation machinery through elF4E-binding protein 1 inactivation. J Biol Chem 287:5042-58. 
A

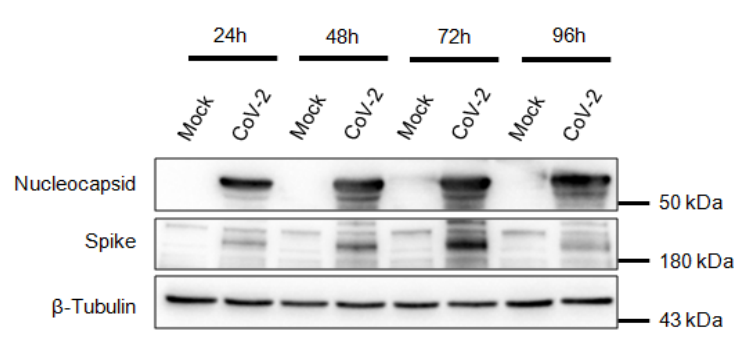

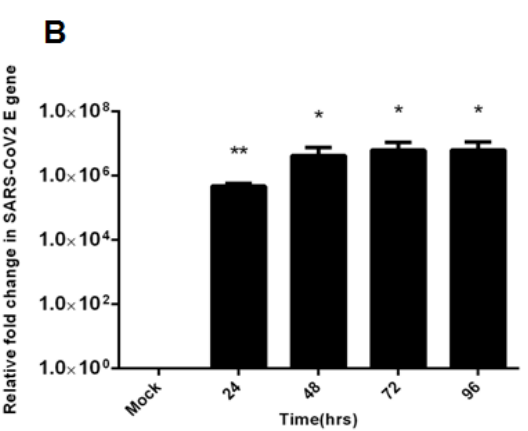

E

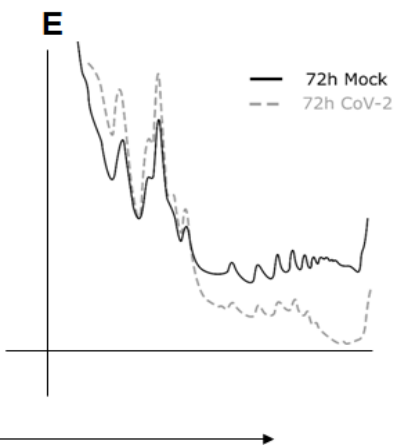

F

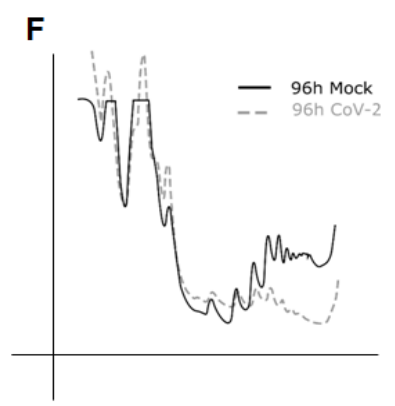

547

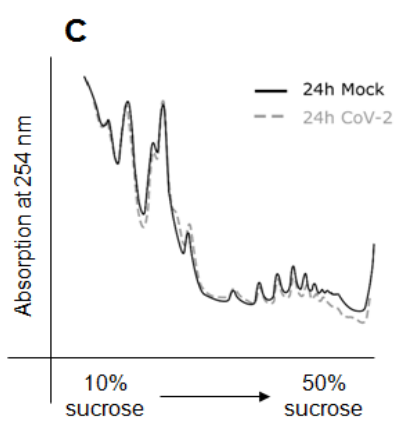

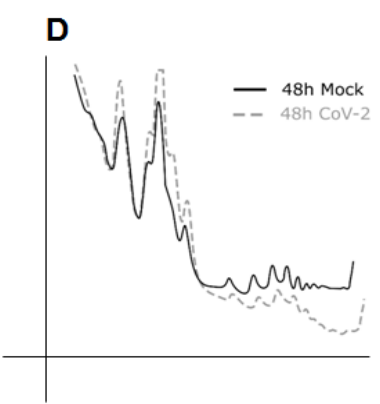

Sedimentation
548

549

550

551

552

553

554

555

556

557

558

559

560

561

562
Figure 1. Polysome profiles of SARS-CoV-2 infected cells demonstrate severe collapse of polysomes. (A) Immunoblot analysis of mock and SARS-CoV-2 infected Caco2 cells over 24, 48, 72, and 96 hours of infection with SARS-CoV-2. Cell lysates were electrophoresed by SDS-PAGE and probed for viral proteins, Nucleocapsid and Spike. (B) Relative fold change in SARS-CoV-2 E gene, quantified through qRT-PCR, across the four time points. Graph represents data from 3 sets and is plotted as mean \pm SEM. $p$-values were calculated using Student's $t$-test and represented as * and **, indicating $p$-values $\leq 0.05$ and 0.005 , respectively. (C-F) Polysome profiles of Caco2 cells infected with SARS-CoV-2 for 24-, 48-, 72- and 96 hours. The cells were treated with $100 \mu \mathrm{g} / \mathrm{mL} \mathrm{CHX}$ before harvesting and lysed in polysome lysis buffer. Equal quantities of lysates were layered onto continuous sucrose gradients ranging from 10$50 \%$, subjected to ultracentrifugation, and fractionated along with measuring absorbance at $254 \mathrm{~nm}$. The digitized profiles for infected and uninfected samples for each time point were overlaid to assess any change in global translation levels. 

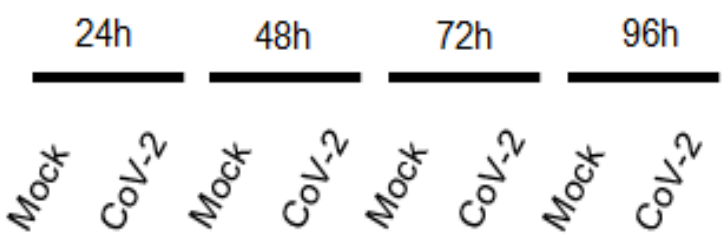
$1 \quad 1.35$
1.48
10.86
0.45

S52 elF $2 \alpha$

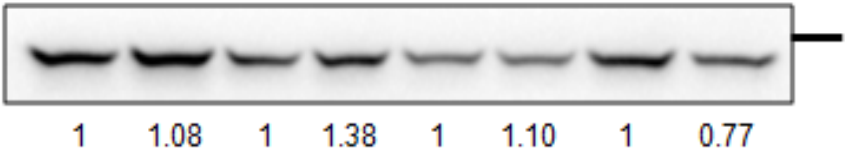

$43 \mathrm{kDa}$

Figure 2. The suppression of translation activities in SARS-CoV-2 infection does

569 not involve elF2 $\alpha$ phosphorylation. Immunoblot analysis of mock and SARS-CoV-2

570 infected Caco2 cells assessing kinetics of phosphorylation of elF2a at S52 and its expression, each normalized against GAPDH. Intensities of phosphorylated and total

572 proteins were separately normalized against GAPDH and the values are represented above the corresponding panel. The phosphorylated residues are marked against the

574 respective panel.

575

576

577

578

579

580

581

582

583 


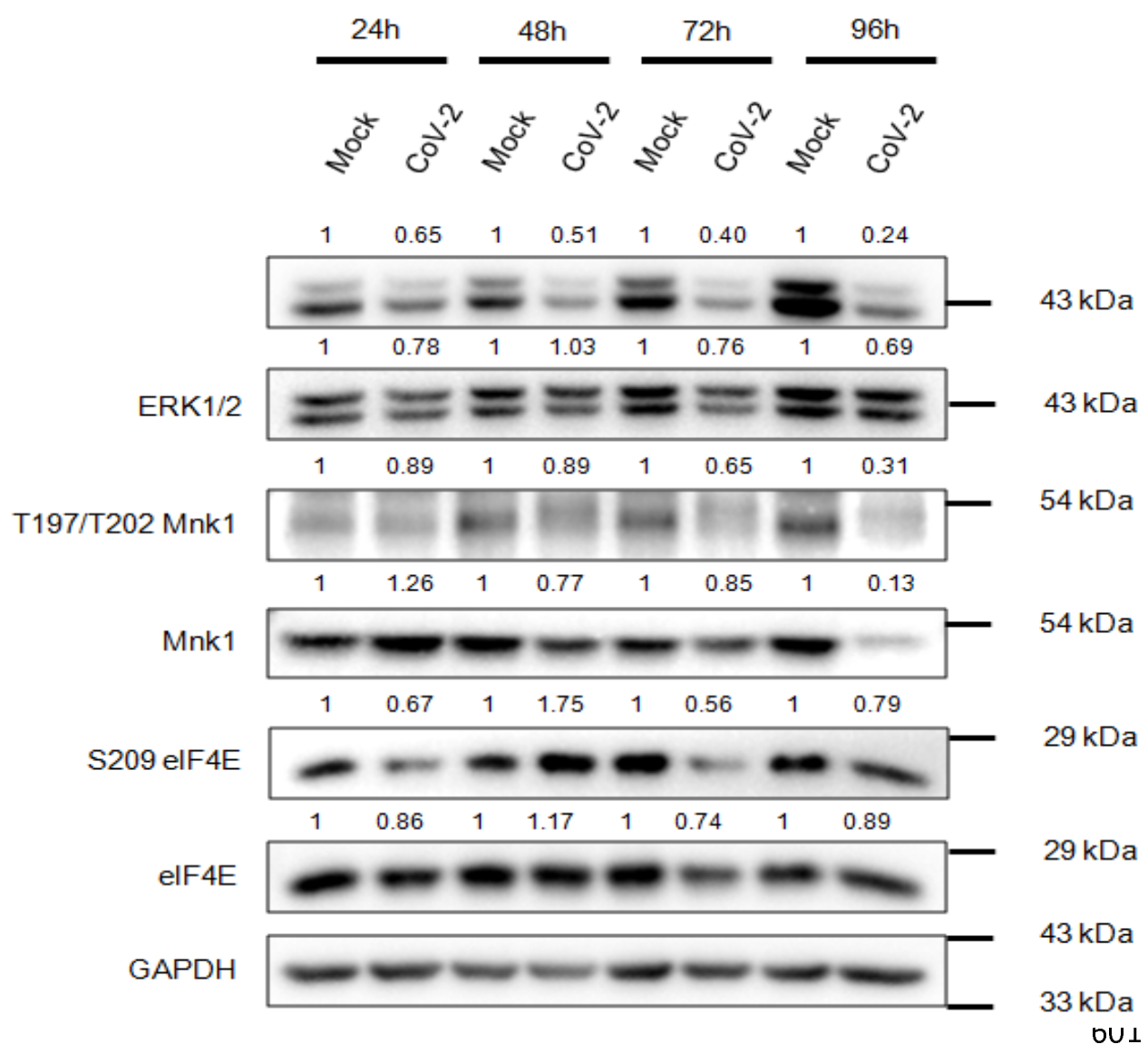

Figure 3. ERK1/2-Mnk1-elF4E axis is inhibited during SARS-CoV-2 infection.

603 Representative immunoblot showing phosphorylation kinetics of ERK1/2, Mnk1 and 604 elF4E in Caco2 cells, normalised against GAPDH, of the panel displayed. Intensities of 605 phosphorylated and total proteins were separately normalized against GAPDH and the values are represented above the corresponding panel. The phosphorylated residues 607 are marked against the respective panel. 
A

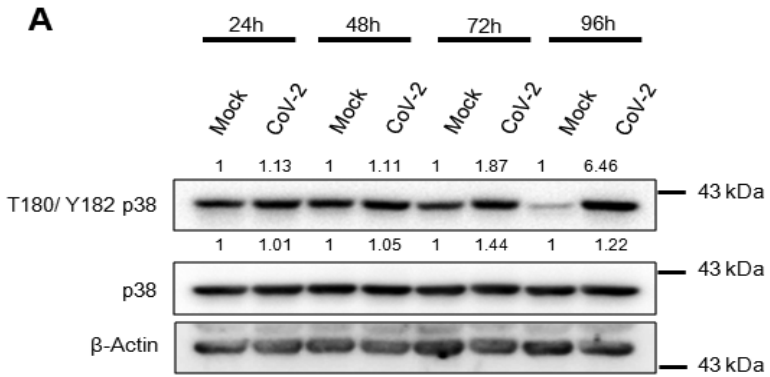

B

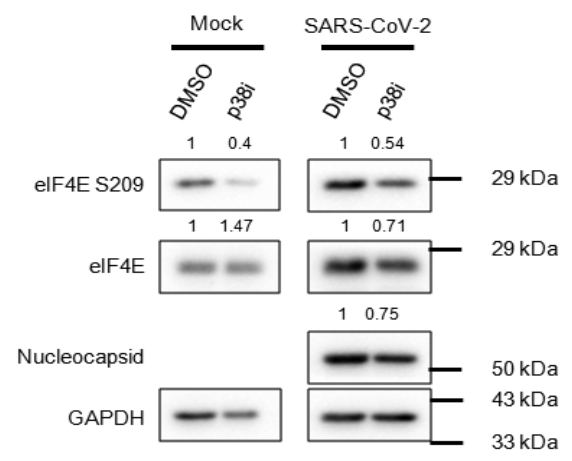

C

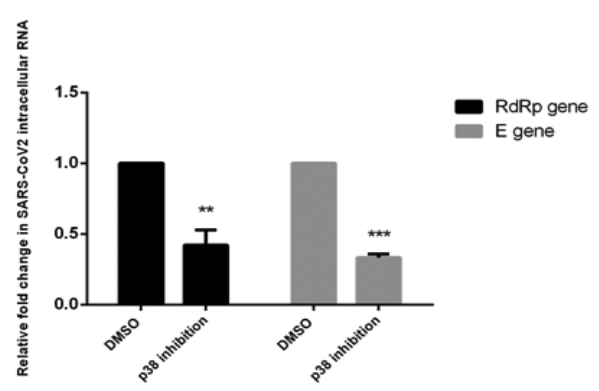

D

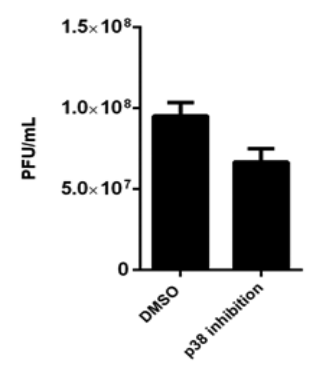

612

613

614

615

616

617

618

619

620

621

622

623

624

625

626

627

628

629

630

Figure 4. Phosphorylated p38MAPK during SARS-CoV-2 infection is beneficial to the viral replication. (A) Immunoblots showing phosphorylation status of p38 at T180/Y182 position along the course of SARS-CoV-2 infection at 24-, 48-, 72-, and 96 hours in Caco2 cells, along with densitometry data of phosphorylation and expression. As in the previous sections, densitometric intensities of phosphorylated and the total proteins were separately normalized against the loading control. (B) SARS-CoV-2 infected cells were treated with p38 VIII inhibitor (p38i) at $10 \mu \mathrm{M}$ concentration for 24 hours beginning at $24 \mathrm{hpi}$ until harvesting. The inhibition was scored by dephosphorylation status of elF4E and viral protein abundance under p38 inhibited environment was also studied. (C) Relative fold change in SARS-CoV-2 intracellular RdRp and E gene RNA, in DMSO and p38-inhibited cells. (D) Infectious virion measure in DMSO and p38-inhibited supernatants, quantified as PFU $/ \mathrm{mL}$. Graphs represent data from at least three sets and are plotted as mean \pm SEM. $p$-values are represented as ** and ${ }^{* * *}$, indicating $p$-values $\leq 0.005$ and 0.0005 , respectively. 
A

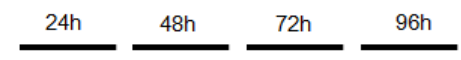

$$
50
$$
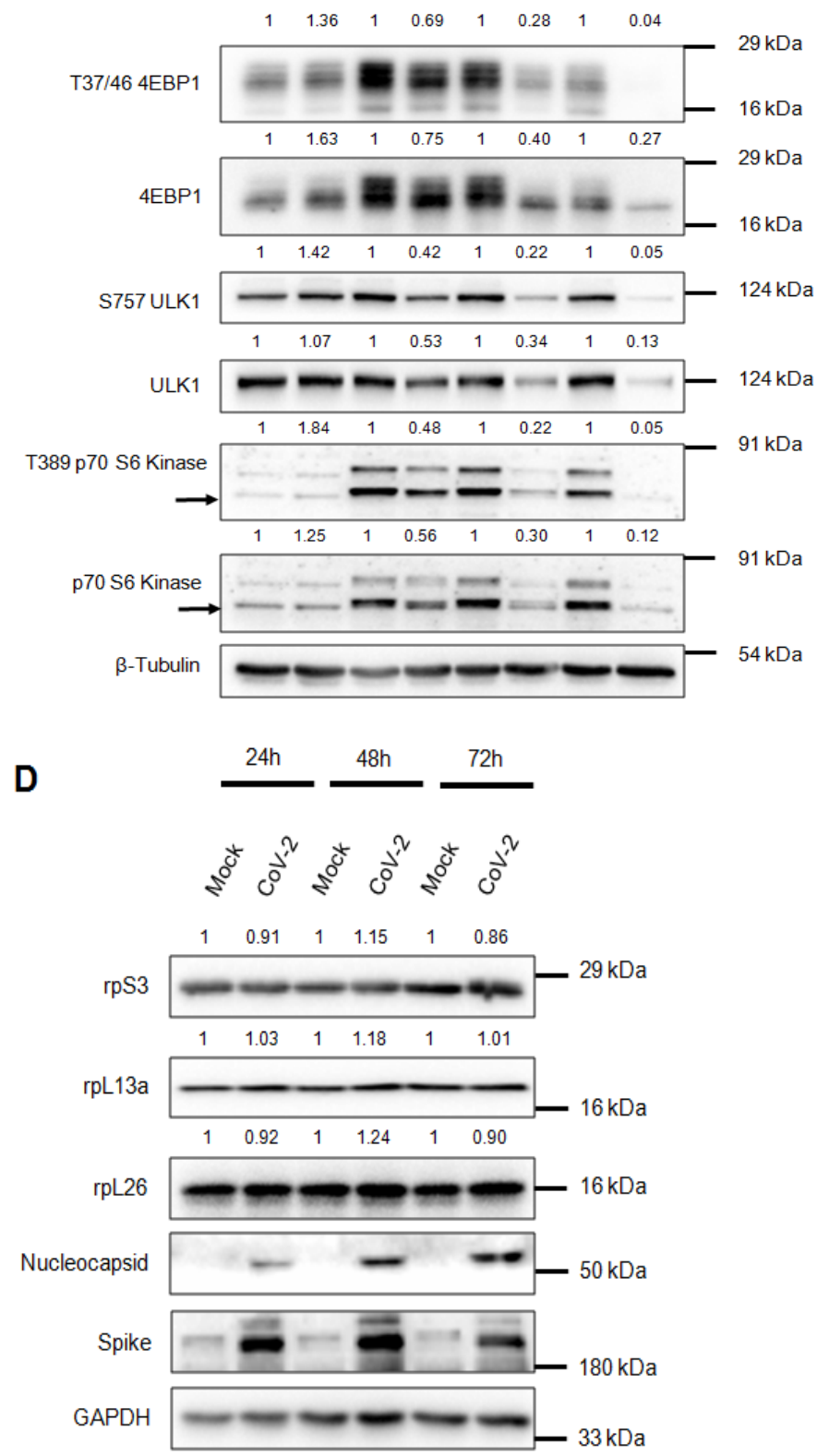

B

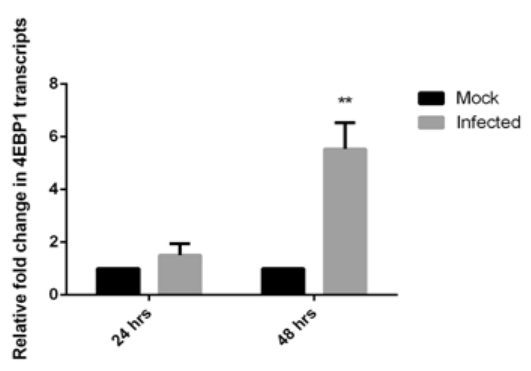

C

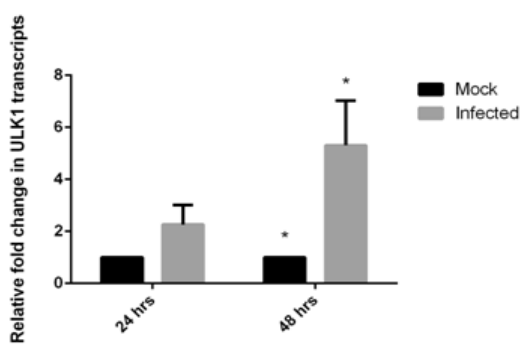

Figure 5. SARS-CoV-2 inhibits mTORC1 and depletes its key substrates. (A) Immunoblots representing status of $\mathrm{mTORC} 1$ kinase activity in mock and infected Caco2 cells through its different substrates- 4EBP1, ULK1, and p70 S6 kinase. The black arrows indicate the appropriate bands corresponding to p70 S6K. Densitometry was performed to measure the intensities of the bands and phosphorylated and total 
650 protein intensities were separately normalized against the loading control. ( $B$ and $C$ ) 651 Relative RNA abundance of 4EBP1 (B) and ULK1 (C) in SARS-CoV-2 infected Huh7

652 cells, respectively. After the infections, total RNA was prepared from the cells and 653 converted to cDNA after which the specific transcripts were quantified by qPCR. (D) 654 Immunoblot analysis of ribosomal proteins S3, L13a, and L26, over the course of 655 infection in Huh7 cells. Densitometric values of each band was normalized against the 656 loading control and the corresponding values are given above the panels. 


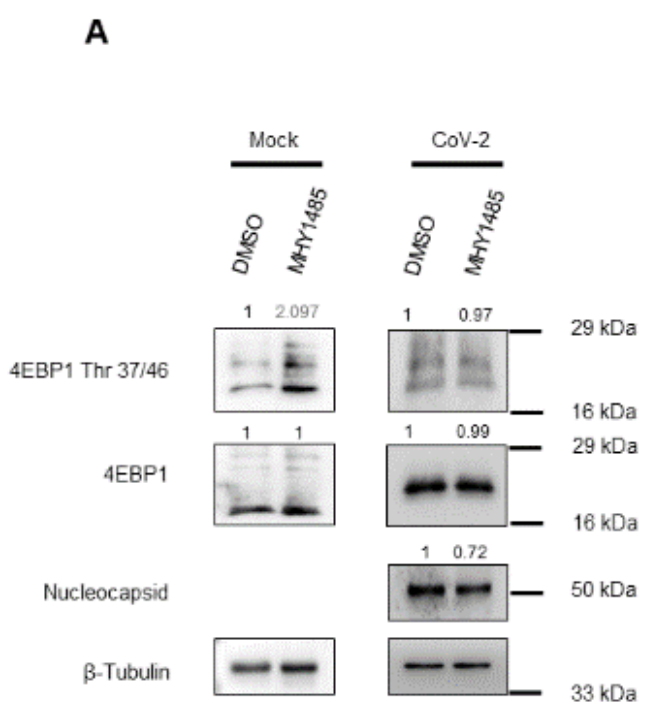

661

Nucleocapsid
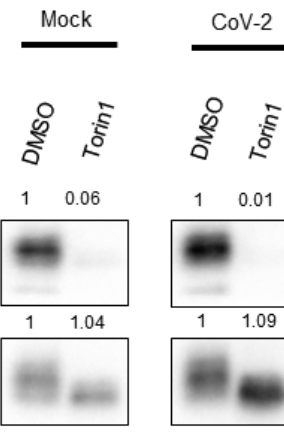

4EBP1 Thr 37/46

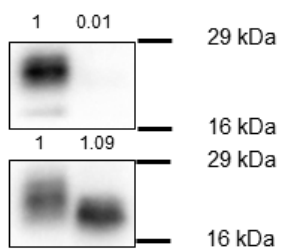

GAPDH
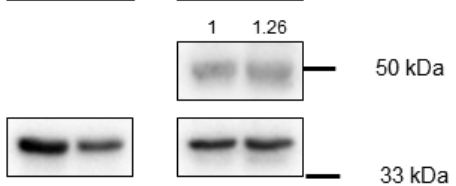

B

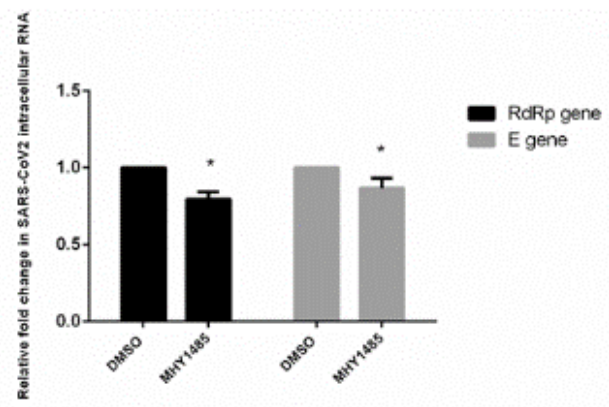

C

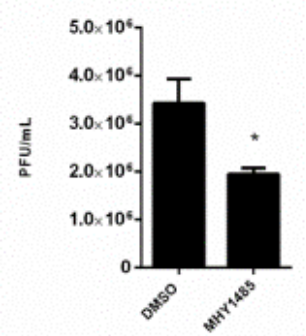

E

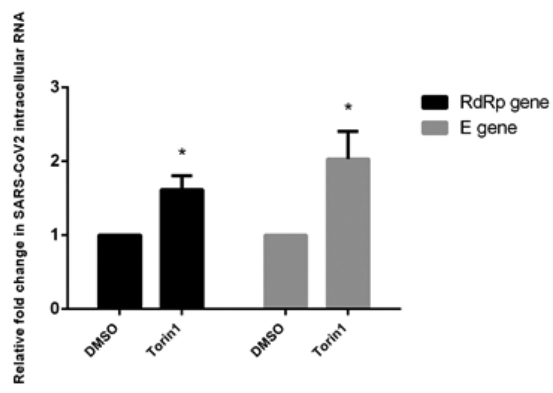

Figure 6. mTORC1 restricts SARS CoV-2 replication. (A) Mock and SARS-CoV-2 infected Huh7 cells were treated with either DMSO or $10 \mu \mathrm{M}$ MHY1485 at $24 \mathrm{hpi}$ and harvested at $48 \mathrm{hpi}$, and successful activation was assessed by increased phosphorylation of 4EBP1 in mock cells treated with MHY1485. Viral protein translation under the conditions of infection was measured through Nucleocapsid levels. (B) Relative fold change in SARS-CoV-2 intracellular RNA in infected cells treated with DMSO or $10 \mu \mathrm{M}$ MHY1485. Viral genes $E$ and RdRP were measured from the RNA samples isolated from the infected or the mock control cells and the relative fold change was represented graphically. (C) Relative measure of infectivity of the supernatant represented as PFU/mL from SARS-CoV-2 infected Huh7 cells treated with DMSO or 
$67310 \mu \mathrm{M}$ MHY1485. (D) Mock and SARS-CoV-2 infected Huh7 cells were infected with

674 SARS-CoV-2 for two hours, treated with either DMSO or 750 nM Torin1 upto 24 hpi and

675 harvested. Similar set up in mock cells was used. Inhibition was assessed by drop in

676 4EBP1 phosphorylation in Torin1 treated mock cells. Viral translation was indicated by

677 Nucleocapsid. (E) Relative abundance of intracellular viral RNA (RdRp and E) from

678 CoV-2 infected Huh7 cells treated with either DMSO or $750 \mathrm{nM}$ Torin1. Graphs are

679 plotted as mean \pm SEM and $p$-values are represented as * indicating $p$-values $\leq 0.05$.

680

681

682

683

684

685

686

687

688

689

690

691

692

693

694

695

696

697

698

699

700

701

702 
704
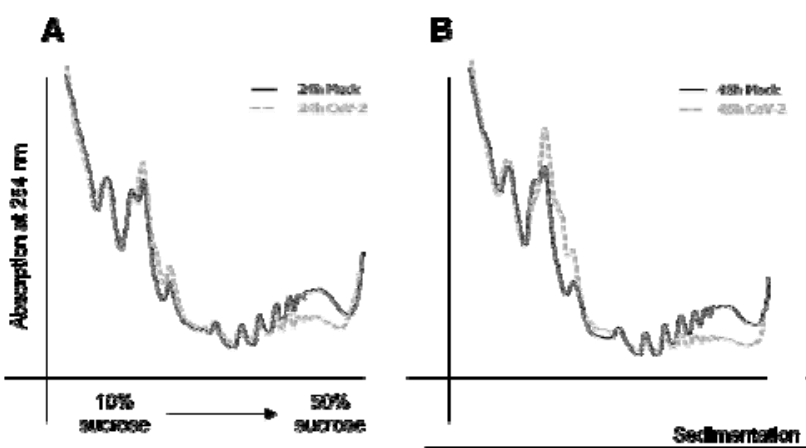

c
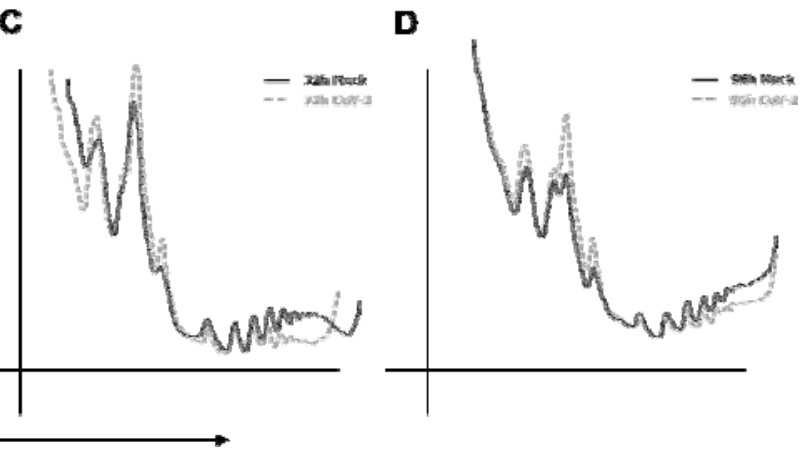

Figure S1: (A-D) Polysome profiles of Caco2 cells infected with another strain of SARSCoV-2 (hCoV-19/India/TG-CCMB-L1021/2020) and processed as mentioned previously in Figure 1. Infected cells were collected at 24-, 48-, 72-, and $96 \mathrm{hpi}$ and were analyzed.

711 Panels A-D represent polysome profiles from these times points in the order of increase

712 time intervals. 


\section{Supplementary figure S2}
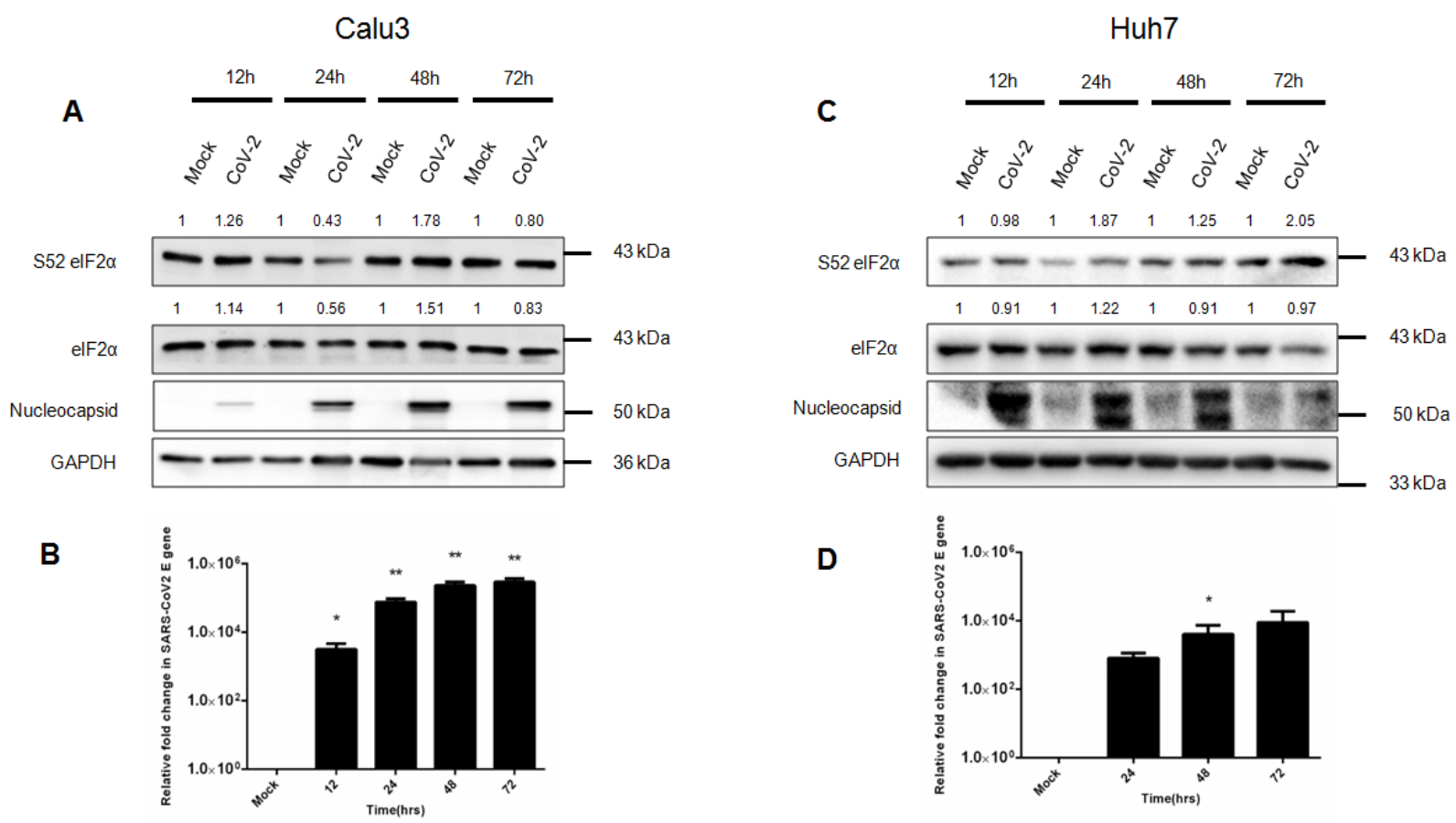
the suppression of translation activities: $(A, C)$ Representative immunoblots showing phosphorylation and expression of elF2a in Calu3 (A), and Huh7 (C) cells, respectively, over 12, 24, 48 and 72 hours. Each panel has densitometric values of fold change in phosphorylation of elF2 $\alpha$ and expression, individually normalized to GAPDH, of the panel displayed. (B, D) qRT-PCR data depicting relative fold change in SARSCoV-2 E gene, along SARS-CoV-2 infection in Calu3 (B), and Huh7 (C) cells. Graphs represent data from 3 sets and are plotted as mean \pm SEM. $p$-values are represented as ${ }^{*}$ and ${ }^{* *}$, indicating $p$-values $\leq 0.05$ and 0.005 , respectively. 


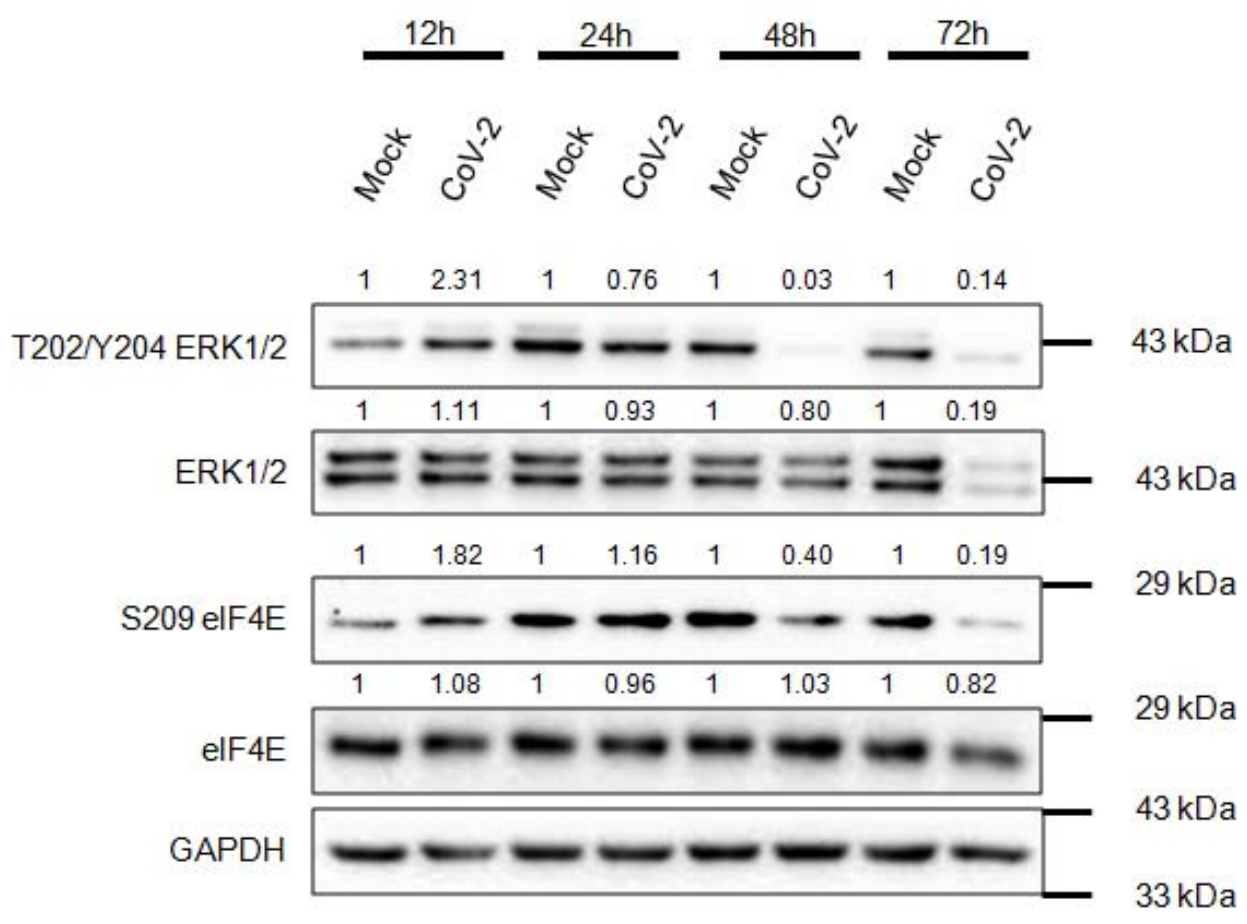
Representative immunoblot of phosphorylation levels of ERK1/2, Mnk1 and elF4E in 


\section{Supplementary figure S4}

765

766

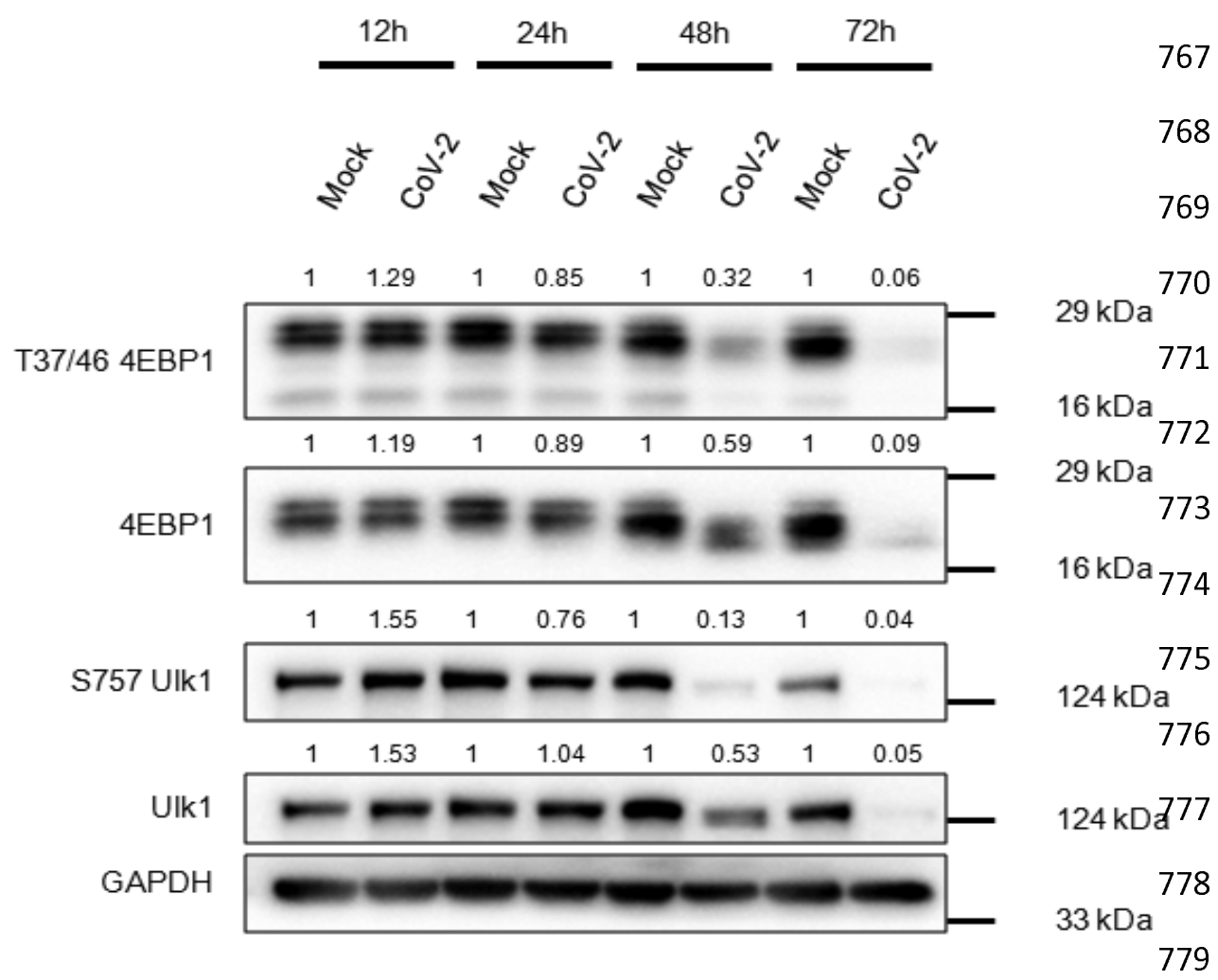

Figure S4: SARS-CoV-2 inhibits $\mathrm{mTORC1}$ and depletes its key substrates. (A)

784 Immunoblots of mTOR substrates, 4EBP1 and ULK1, from mock and infected Huh7

785 cells showing their phosphorylation as well as expression as indicated in the

786 densitometric values above each blot.

787 